present to participate fully, equally and without prejudice to their positions in the Conference.

The text of the tentative draft constitution for the proposed Organization consists of seven sections. It opens with a statement of the underlying reasons why international co-operation in educational reconstruction should be attempted. The functions of the projected Organization are then defined in terms which should permit it to work effectively in the fields of educational and cultural rehabilitation and reconstruction, and to develop ultimately into a permanent body with broader activities. Membership is to be open to all the United Nations and Associated Nations and to such other nations as shall be accepted by the assembly, upon application thereto, after the cessation of hostilities with the Axis Powers. Provision is made for an assembly with equal representation and votes for all member States, an executive board to be elected by the assembly and an international secretariat. The financial section states that administrative expenses shall be shared by the member nations on a basis to be agreed by the assembly. It also provides for the creation of an Emergency Rehabilitation Fund controlled by a committee, which will fix contributions and also make allocations from the Fund. The committee will consist of representatives of the three States making the largest contributions for administrative expenses and three members elected by the executive board. Member nations would be required to supply information about education and cultural matters. Provision is also made for defining the legal status of the Organization and its staff, providing for co-operation between the Organization and existing international organizations in the educational and cultural fields, and goverming the relationship of the Organization to any agency for co-ordinating public international organizations.

\section{Clinical Use of Penicillin}

ThE issue of the British Medical Journal dated April 15 includes eight papers which record the results of work done at one of the four main centres established in March 1943 by the Penicillin Clinical Trials Committee of the Medical Research Council. A leading article comments on these papers and on other work in the United States, where much larger supplies of penicillin are available, so that work on a larger scale is possible. In the first article, Prof. L. P. Garrod and Dr. Christie describe the work and policy of the centre at which all this work was done. Other articles deal with the systemic administration of penicillin by continuous intravenous drip, intramuscular injection, drip transfusion into the bone marrow of the sternum and continuous intramuscular drip transfusion; with the effects of penicillin on infections of the mandible and of bone, the latter indicating that treatment of chronic bone infections is not yet satisfactory ; with its use as a local application to lesions of soft tissues (wounds, abscesses, cellulitis and infected skin eruptions); and its effects on breast abscess and certain skin diseases.

A final article by Prof. Garrod explains the extensive laboratory work which is necessary if the clinical work is to be properly controlled. Penicillin is supplied in the form of a powder or tablets and solutions have to be made from these. Because penicillin is a very labile substance, and because many bacteria are quite unaffected by it and may, therefore, live in these solutions or even decompose them so that they lose their activity, the greatest care is necessary in making up the solutions. Further, it is advisable to determine, before treatment, what micro-organism is being treated and the sensitivity of the particular strain concerned, because certain strains of some kinds of bacteria (especially Staphylococcus) vary in their resistance to penicillin. It is also necessary to obtain swabs from the patients to check by in vitro methods the effects of treatment. Because the therapeutic effect depends on keeping up a sufficient concentration of penicillin in the lesion, the concentration actually being maintained must be ascertained from samples taken from the patient. Estimations of the penicillin content of the blood are also done.

It will do no harm, perhaps, to repeat Prof. Garrod's reminder that it is of the first importance to realize that penicillin acts only on certain bacteria, most of which are Gram-positive, the chief exceptions being the gonococcus and meningococcus ; and that certain bacteria are highly resistant to it. On the other hand, it has, he says, enormous antiseptic power, is almost completely indifferent to the medium in which it acts and almost completely non-toxic to the body as a whole. Clearly everything possible is being done in Great Britain and elsewhere to apply this remarkable antibacterial substance to the relief of suffering in man and animals. Those who impatiently demand quicker progress are evidently unaware of the great difficulties involved, and are often incapable of assessing the scientific care required, or the dangers of drawing premature conclusions from the extensive experimental work that is being done.

\section{Warrington Yorke Memorial Fund}

THE death of Prof. Warrington Yorke, tragically unexpected by those who knew his vigour and force of character, was a great loss to the Liverpool School of Tropical Medicine and to medicine and biology. His work on the trypanosomes, the nematodes and on other parasitic and tropical diseases earned for him an intermational reputation, and his later work on the chemotherapy of parasitic diseases was of equal value. It is said of him (Brit. Med.J., April 15) that his introduction of drugs of the diamidine series is making it possible to master kala-azar in places where it is resistant to compounds of antimony, and tribute is paid to his efforts to place British chemotherapy in the front rank. Not only the former colleagues and friends of Warrington Yorke, but also all who respect and admire scientific ability and devoted effort to apply it to the relief of human and animal suffering, will like to know that their admiration may take a practical form. The Council of the Liverpool School of Tropical Medicine is appealing for funds to establish the Chemotherapeutic Research Department of that School as a fitting memorial to Warrington Yorke, who started the work now going on in it. Subscriptions may be sent to the Hon. Treasurer, Warrington Yorke Memorial Fund, Chamber of Commerce, 1 Old Hall Street, Liverpool.

\section{Tattersall Memorial Fund}

Past and present students of the Department of Zoology, University College, Cardiff, have opened a Tattersall Memorial Fund, the object of which is to found a studentship in zoology in the College as a memorial to the late Prof. W. M. Tattersall, who died on October 5, 1943. The organizers of the Fund also desire to invite the many friends of Prof. Tattersall, particularly zoologists, in various parts of tho world, to join them in perpetuating his memory. 